\title{
A Study of Silicon Crystallization Dependence upon Silicon Thickness in Aluminum-induced Crystallization Process
}

\author{
Doo Won Lee, Muhammad Fahad Bhopal, and Soo Hong Lee* \\ Green Strategic Energy Research Institute, Department of Electronics Engineering, Sejong University, \\ Seoul 05006, Republic of Korea
}

\begin{abstract}
Aluminum-induced crystallization(AIC) is one of the ways to improve characteristics of thin-film poly-crystalline (TFPC) silicon solar cell since it shows large grain size and good properties for TFPC silicon solar cell. In AIC process, aluminum is firstly deposited on foreign substrate. Then, silicon is deposited on aluminum. Annealing was done below the eutectic temperature of aluminum and silicon $\left(577^{\circ} \mathrm{C}\right)$. Afterward, amorphous silicon layer is crystallized by aluminum-inducing process. In this paper, we report amorphous silicon layer thickness effects to crystallized silicon and hillock characteristics since the amorphous silicon layer is important layer for AIC.Crystallized silicon properties were analyzed dependent upon silicon thickness (50 \% - $200 \%$ than aluminum layer thickness). In case of the thick amorphous silicon (above 300 $\mathrm{nm}$ ), hillocks grew on the crystallized silicon layer, Even though silicon hillock showed high crystallinity as a result of Raman spectroscopy, it had not enough grain size (average $4 \mu \mathrm{m}$ ). Therefore, as results, samples which had $113 \%$ - $120 \%$ silicon and aluminum thickness ratio showed proper thickness to use as a seed layer.
\end{abstract}

(Received February 19, 2018; Accepted March 16, 2018)

Keywords: crystallization, solar cells, silicon

\section{INTRODUCTION}

Use of thin-film poly-crystalline (TFPC) silicon solar cell on foreign substrates is one of the ways to reduce levelized cost of energy (LCOE) of the silicon solar cell. Research trends in TFPC silicon solar cell using foreign substrates are usually focused on enlarging silicon grain size. Silicon absorb layer is deposited using atmospheric pressure chemical vapor deposition (APCVD) [1] or rapid thermal chemical vapor deposition (RTCVD) [2]. Then, the silicon is processed by zone-melting recrystallization (ZMR) to increase the grain size [3-5]. A process based on seed layer formation also has been reported to enlarge silicon grain size in several institutes. The seed layer process is an important technology for TFPC silicon solar cells. One of seed layer technologies is metal induced crystallization using nickel [6,7], aluminum [8-10],

*Corresponding Author: Soo Hong Lee [Tel: +82-2-3408-3726, E-mail: shl@sejong.ac.kr] Copyright (C) The Korean Institute of Metals and Materials etc. Aluminum-induced crystallization (AIC) is a common method since silicon seed layer which is formed by AIC has large silicon grain size and back surface field (BSF) property [11,12]. The conventional process of AIC is firstly aluminum is deposited on a foreign substrate. Then, aluminum is exposed in the air to deposit native aluminum oxide. After the exposure, silicon is deposited on the native aluminum oxide layer. The AIC sample is annealed below the eutectic temperature of aluminum and silicon for silicon crystallization. After the annealing process, the layers are exchanged and silicon is crystallized. This process is also called aluminum-induced layer exchange (ALILE) [13]. Aluminum and aluminum oxide layers on the crystallized silicon after the annealing are etched to use the crystallized silicon layer as a seed layer. In AIC process, the aluminum and silicon thickness and the annealing temperature are important factors to enlarge grain size and improving quality of crystallized silicon. Usually, silicon layer is thicker than aluminum layer [13]. On the other hand, silicon and aluminum layers thickness ratio and the analysis 

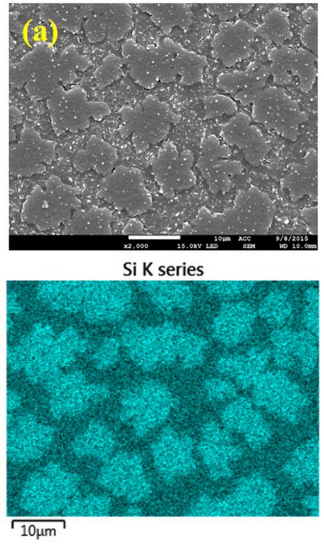
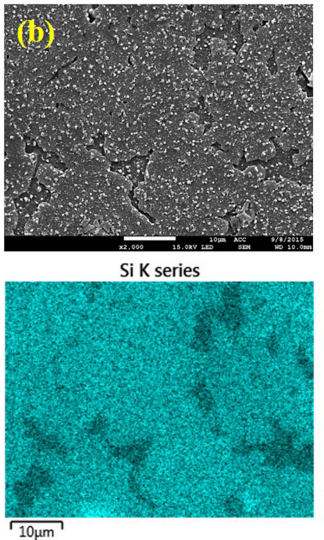
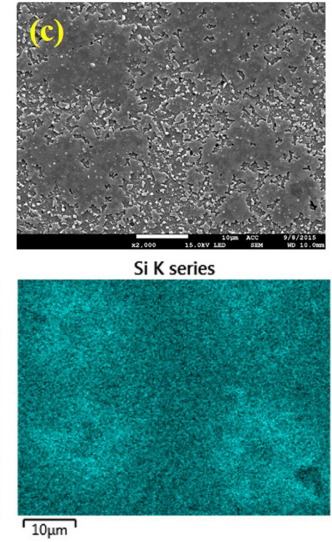

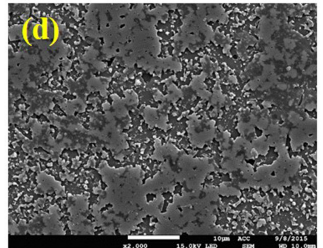

Si K series

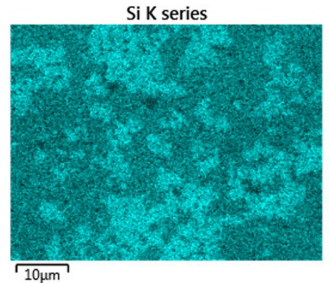

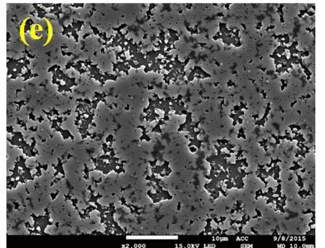

Si K series

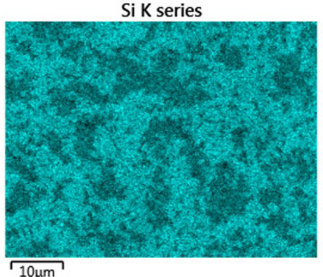

Fig. 1. FE-SEM, EDX results dependence on silicon thickness after crystallization; (a) silicon $200 \mathrm{~nm}$, (b) silicon $300 \mathrm{~nm}$, (c) silicon 400 $\mathrm{nm}$, (d) silicon $500 \mathrm{~nm}$, (e) silicon $600 \mathrm{~nm} /$ aluminum $300 \mathrm{~nm}$.

of the crystallized silicon layer dependence upon silicon layer thickness still need research. Therefore, in this paper, the silicon layer thickness was increased from $50 \%$ to $200 \%$ than aluminum layer thickness to analyze the crystallized silicon quality and the effects depend upon silicon thickness.

\section{EXPERIMENTALS}

Borosilicate glass substrates were used as a foreign substrate in this experiment. $300 \mathrm{~nm}$ aluminum layer was deposited using electron-beam evaporator. Aluminum deposition rate was $1.0-1.5 \AA / \mathrm{s}$. Then, the samples were exposed in the air to deposit native aluminum oxide for 24 hours. After exposure in the air to form native aluminum oxide, amorphous silicon was deposited on the native aluminum oxide by electron-beam evaporator at $1.0-1.5 \AA / \mathrm{s}$. Silicon layer thickness was accordingly adjusted in comparison with aluminum layer thickness. Ratio of silicon layer thickness was changed from $50 \%$ to $200 \%$ of the aluminum layer thickness. Silicon and aluminum layer thickness and deposition rate were controlled by thickness monitor (STM-100/MF). To exchange silicon and aluminum layers, each sample was annealed by a furnace at $425^{\circ} \mathrm{C}$ in nitrogen atmosphere. For relative comparison, all samples annealed for 40 hours to completely crystallize the silicon layer and consume all of deposited amorphous silicon. After crystallization annealing process, aluminum layer and native aluminum oxide layer on crystallized silicon layer were etched using aluminum etching solution (phosphoric acid based solution) for an hour. Surface morphology of crystallized silicon layer was analyzed using field emission scanning electron microscope (FE-SEM, nontilt and 70-degree tilt) and optical microscope. Energy dispersive $\mathrm{x}$-ray spectroscopy (EDX) measurement was used for the component analysis. Accordingly, X-ray diffraction (XRD) measurement was conducted to analyze phases of crystallized silicon layer. Electron backscatter diffraction (EBSD) was also measured to determine the grain size.

\section{RESULTS \& DISCUSSION}

Surface morphology was firstly analyzed by using FE-SEM (non-tilt). In the case of $200 \mathrm{~nm}$ silicon/300 $\mathrm{nm}$ aluminum sample, the surface morphology showed small island shapes since there was insufficient silicon supply compared to aluminum thickness (Fig. 1(a)). Surface morphology of $300 \mathrm{~nm}$ silicon/300 nm aluminum sample showed that larger island shape than $200 \mathrm{~nm}$ silicon sample. Moreover, crystallized silicon islands of $300 \mathrm{~nm}$ silicon sample almost covered entire surface area due to sufficient silicon supply in compared with aluminum thickness. However, there is still uncovered area at $300 \mathrm{~nm}$ silicon sample. Besides, it was noteworthy that there were small 


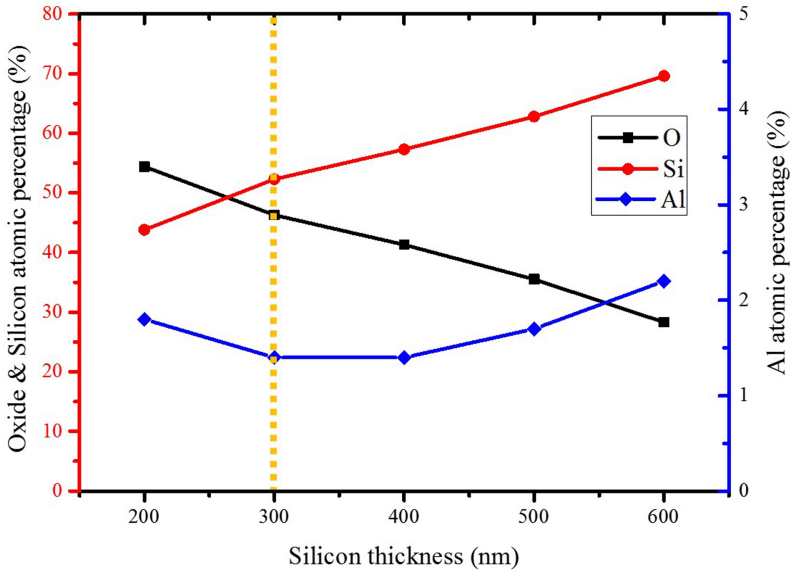

Fig. 2. EDX results analysis dependence upon silicon layer thickness.

silicon particles on crystallized silicon regardless of silicon layer thickness. These small particles were distinguished as silicon by EDS result (Fig. 2). The small particles were called silicon hillocks. The reason for hillocks generation is related with the mechanism of AIC [14]. Silicon diffusion process of AIC is usually four routes available. (1) Diffusion inside the aluminum grains, (2) Diffusion along aluminum grain boundaries (the aluminum films is naturally nanocrystalline), (3) Diffusion along the aluminum/ amorphous silicon interface (native oxide layer), (4) Diffusion along the substrate/Al interface. Diffusion paths (2), (4) are the main diffusion paths to decide a net diffusion rate in normal AIC [13]. After silicon diffusion, if the silicon concentration reached to the silicon saturation concentration in the main diffusion paths, the silicon nucleation starts at the same time. Therefore, in this experiment, the silicon hillock and crystallized layer simultaneously were formed. These results correlated the fact with that the activation energy for nucleation energy of the silicon hillock and seed layer has similar values [15]. According to the silicon nucleation theory, even insufficient silicon supplying in AIC, the hillock was formed on the surface in this experiment. However, density of silicon hillocks at $300 \mathrm{~nm}$ silicon sample had a higher amount due to a sufficient silicon supply. Surface morphology of $400 \mathrm{~nm}$ silicon/300 nm aluminum sample showed that the surface was covered with crystallized silicon, consisting with large island and small shapes hillocks. According to the small shapes hillocks, surface roughness increased than $300 \mathrm{~nm}$ silicon sample since silicon was over supplied. After $400 \mathrm{~nm}, 500 \mathrm{~nm}$, and $600 \mathrm{~nm}$ silicon thickness samples showed that silicon hillocks size also grew according to over silicon supply (Fig 1 (c), (d), (e)). On the other hand, according to the over silicon supply, additional silicon crystallization on the hillocks was not observed since the silicon nucleation was started in the main silicon diffusion paths.

EDX analysis simultaneously analyzed with FE-SEM. Fig. 2 shows EDX data with the atomic percentages of aluminum, silicon in the crystallized silicon and hillocks dependence upon silicon layer thicknesses $(200,300,400,500,600 \mathrm{~nm})$. Atomic percentage of silicon increased steadily from $200 \mathrm{~nm}$ to $600 \mathrm{~nm}$ silicon thickness. In case of the oxide, the atomic percentage decreased in proportion to increase the atomic percentage of silicon. On the other hand, atomic percentage of aluminum showed a different trend. The atomic percentage moderately declined until the $300 \mathrm{~nm}$ silicon thickness. Due to increasing crystallized silicon and hillocks after $300 \mathrm{~nm}$ silicon thickness, atomic percentage of aluminum was increased in proportion to atomic percentage of silicon.

Quality of crystallized silicon is also an important factor to TFPC solar cells. One of methods to analyze the quality of crystallized silicon is Raman spectroscopy. Conventionally, according to results of Raman spectroscopy, amorphous silicon shows a peak at $480 \mathrm{~cm}^{-1}$, poly-crystalline silicon shows a peak at $510 \mathrm{~cm}^{-1}$, and single crystalline silicon shows a peak at $520 \mathrm{~cm}^{-1}$ [12]. According to increasing crystallinity of the silicon layer, Raman peak moves from $480 \mathrm{~cm}^{-1}$ to $520 \mathrm{~cm}^{-1}$. Therefore, in this experiment, quality of crystallized silicon layer was measured by Raman spectroscopy mapping process. The scanned area with Raman spectroscopy was $30 \mu \mathrm{m} \times 35 \mu \mathrm{m}$. Results of Raman spectroscopy were normalized in compare with the quality of crystallized silicon dependence upon silicon thickness (Fig. 3). The normalization was per- 


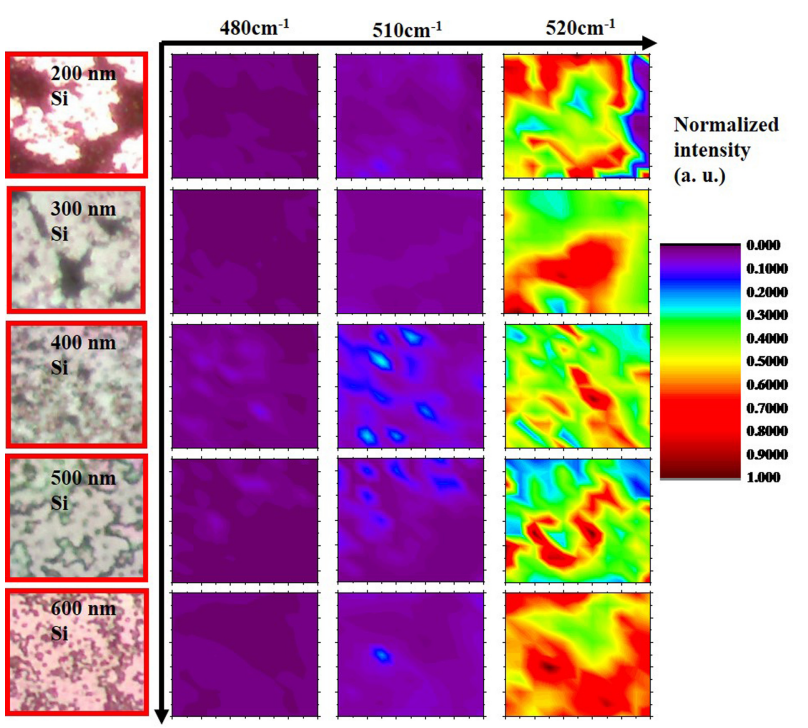

Fig. 3. Raman spectroscopy mapping results dependence upon silicon layer thickness.

formed by maximum values of 480, $510,520 \mathrm{~cm}^{-1}$ Raman shift of each sample. As a result of Raman spectroscopy mapping, regardless of the silicon layer thickness, all crystallized silicon area showed good quality of silicon layer since most of the area had a peak at $520 \mathrm{~cm}^{-1}$. While a sample which was processed by $400 \mathrm{~nm}$ silicon layer thickness partly showed the poly-crystalline silicon intensity $\left(510 \mathrm{~cm}^{-1}\right)$ since newly formed silicon hillocks effected to silicon qual- ity. On the other hand, intensity of poly-crystalline silicon continuously decreased by the growth of silicon hillocks after $500 \mathrm{~nm}$ silicon layer thickness.

As a result of Raman spectroscopy, silicon hillocks were also shown good crystallinity to use as a seed layer since silicon hillocks which were also grown on the ordinary crystallized silicon when the silicon layer was $200 \%$ thicker than the aluminum layer. Moreover, its surface was very flat (Fig. 3). It was noteworthy that the silicon hillock could be used as a seed layer too as a result of the Raman spectroscopy. However, EBSD results showed different results (Fig. 4). Colored area showed silicon grain size and black area showed that it has no intensity (Fig. 4). As a result of EBSD, silicon islands in the $200 \mathrm{~nm}$ silicon sample showed crystallized silicon (Fig. 4(a)). However, the other black area of silicon island shape had no grain size since the roughness usually effected to EBSD results. $300 \mathrm{~nm}$ silicon sample showed that almost area was covered by crystallized silicon except for black areas. Maximum crystallized silicon grain size showed above $20 \mu \mathrm{m}$. As EBSD results of $400,500,600 \mathrm{~nm}$ silicon/300 nm aluminum samples, EBSD pattern was not clearly shown due to increase of the crystallized silicon surface
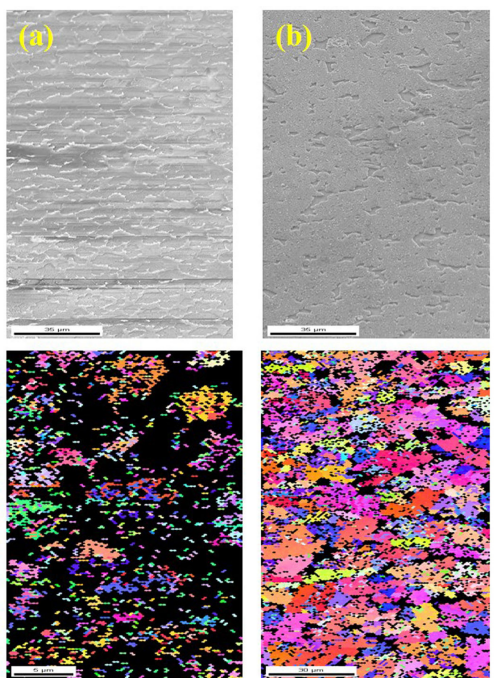
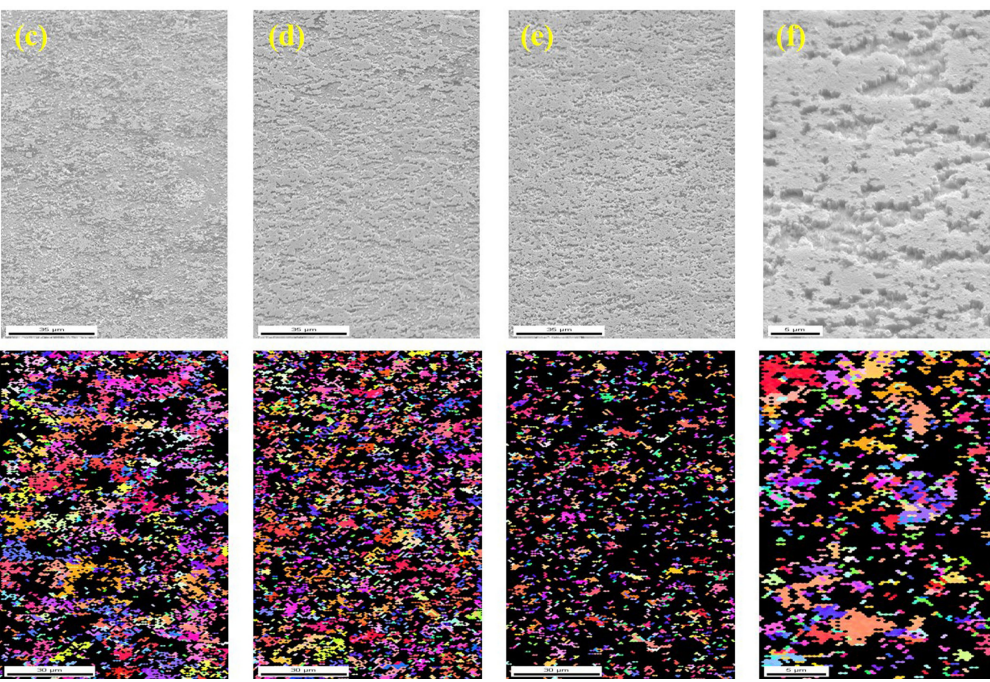

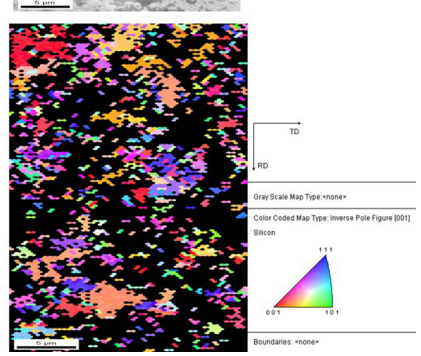

Fig. 4. FE-SEM image after tilting 70 degree(above) and EBSD result(below) results dependence upon silicon thickness after crystallization; (a) silicon $200 \mathrm{~nm}$, (b) silicon $300 \mathrm{~nm}$, (c) silicon $400 \mathrm{~nm}$, (d) silicon $500 \mathrm{~nm}$, (e) silicon $600 \mathrm{~nm} /$ aluminum $300 \mathrm{~nm}$. (f) A enlarged image of the silicon $600 \mathrm{~nm} /$ aluminum $300 \mathrm{~nm}$ sample. 


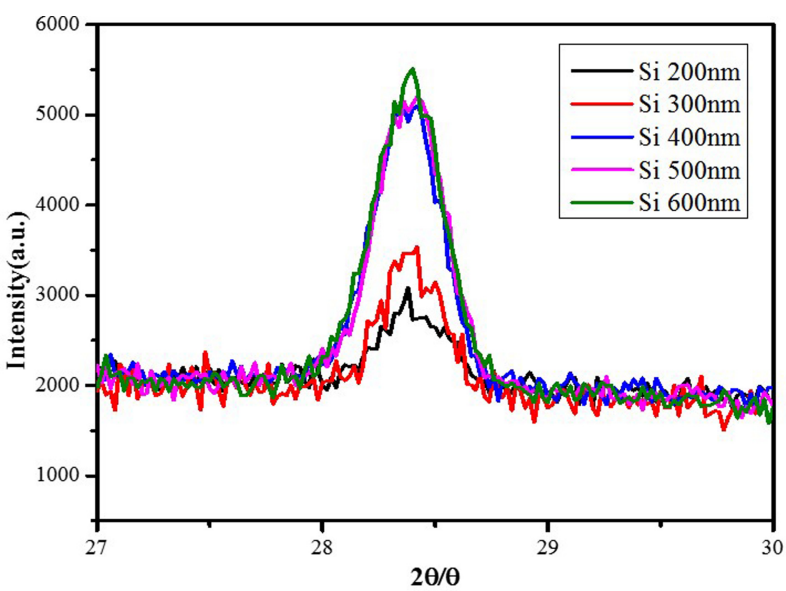

Fig. 5. XRD measurement results; the silicon hillock shows highly oriented (111) silicon phase.

roughness by silicon hillocks. However, in case of the $600 \mathrm{~nm}$ silicon/300 $\mathrm{nm}$ aluminum, the silicon hillocks also showed silicon grains while the grain size was below $4 \mu \mathrm{m}$ (Fig. 3(f)). Therefore, use of silicon hillocks was difficult to use as a seed layer due to the small grain size. Moreover, increase of surface roughness after $400 \mathrm{~nm}$ was also one of disadvantages to use these layer as a seed.

Phase of the crystallized silicon was also analyzed using XRD (Fig. 5). As a result of XRD, silicon (111) phase was remarkably increased from $400 \mathrm{~nm}$ silicon layer thickness while other silicon phase had not difference. Intensity of silicon (111) phase grown in proportion to density of silicon hillocks. Dominant silicon phase of hillocks normally showed (111) direction. In literature, phase of (111) direction silicon usually shows in the defect in crystallized silicon [16]. Therefore, the proper silicon thickness ranges were to prevent hillocks is from $300 \mathrm{~nm}$ to $400 \mathrm{~nm}$ silicon. Experiment varied silicon thickness from $300 \mathrm{~nm}$ to $400 \mathrm{~nm}$ silicon was additionally processed.

According to results of an optical microscope with 300 to $400 \mathrm{~nm}$ silicon thickness, silicon hillocks shows on the surface with a gray color (Fig. 6). Covered area with crystallized silicon was continually increased in proportion to silicon layer thickness while the density of silicon hillocks was rapidly increased after 360 $\mathrm{nm}$ silicon thickness. Therefore, proper silicon layer
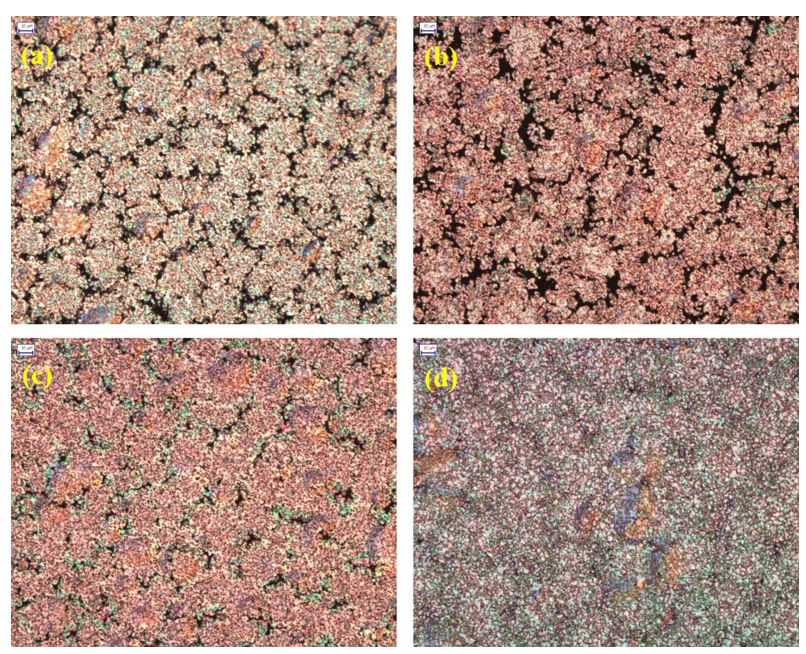

Fig. 6. Optical microscope images after crystallization of (a) silicon $320 \mathrm{~nm} /$ aluminum $300 \mathrm{~nm}$, (b) silicon $340 \mathrm{~nm} /$ aluminum $300 \mathrm{~nm}$, (c) silicon $360 \mathrm{~nm} /$ aluminum $300 \mathrm{~nm}$, (d) silicon $380 \mathrm{~nm} /$ aluminum $300 \mathrm{~nm}$.

thickness is from $340 \mathrm{~nm}$ to $360 \mathrm{~nm}$.

\section{CONCLUSION \& FUTURE WORK}

Our investigation showed crystallized silicon and hillock characteristics dependence upon silicon thickness effects on AIC process. Even though insufficient silicon supplying in AIC, the hillock was formed on the crystallized silicon surface in every condition. Interestingly, the silicon hillocks were also growth when the silicon layer thickness thicker than aluminum layer. Moreover, Raman spectroscopy also showed that the silicon hillocks had an intensity at the $520 \mathrm{~cm}^{-1}$. However, as a result of EBSD, actual silicon grain size of the hillocks was illustrated below $4 \mu \mathrm{m}$ due to the primary small hillock size. Therefore, although the silicon hillocks were also grown according to increase the silicon thickness, the grain size of grown hillock was relatively small for the seed layer. As results of an additional experiment, samples which had $113 \%-120 \%$ silicon and aluminum thickness ratio showed proper thickness to use as a seed layer since it was covered the surface area with silicon and had less the silicon hillocks. As a future work, we are going to making solar cells and comparing the characteristics dependence upon silicon layer thickness. 


\section{ACKNOWLEDGMENT}

This work was supported by the Korea Evaluation Institute of Industrial Technology (KEIT) granted financial resource from Ministry of Trade, Industry, and Energy, Republic of Korea (No. 10043793), and thank all colleagues at the Green Strategic Energy Research Institute, Department of Electronics Engineering, Sejong University.

\section{REFERENCES}

1. S Bau. "High-temperature CVD silicon films for crystalline silicon thin-film solar cells,” $\mathrm{Ph}$. D. Thesis, Universität Konstanz, Konstanz (2003).

2. G. Stollwerck, S. Reber, and C. Haessler, Adv. Mat. 13, 1820 (2001).

3. R. Ludemann, S. Schaefer, C. Schule, and C. Hebling, In Photovoltaic Spec. Conf., 159, Anaheim, California (1997).

4. T. Kieliba, S. Bau, D. Oßwald, and A. Eyer, In Proceedings of 17th European Photovoltaic Sol. Energ. Conf. WIPRenewable Energies, 1604, Munich and ETA, Florence
(2001).

5. S. Kühnapfel, S. Gall, B. Rech, and D. Amkreutz, Sol. Energ. Mat. Sol. C 140, 86 (2015).

6. Z. Jin, G. A. Bhat, M. Yeung, H. S. Kwok, and M. Wong, $J$ Appl. Phys. 84, 194 (1998).

7. A. R. Joshi and K. C. Saraswat, IEEE T. Electron Dev., 50, 1058 (2003).

8. D. V. Gestel, I. Gordon, H Bender, D. Saurel, J Vanacken, G Beaucarne, et al., J Appl. Phys. 105, 114507 (2009).

9. I. Gordon, L. Carnel, D. V. Gestel, G. Beaucarne, and J. Poortmans, Thin Solid Films 516, 6984 (2008).

10. O. Nast and A. J. Hartmann, J Appl. Phys. 88, 716 (2000).

11. I. Gordon, L. Carnel, D. V. Gestel, and G. Beaucarne, J. Poortmans, Prog. Photovoltaics 15, 575 (2007).

12. D. W. Lee, M. F. Bhopal, and S. H. Lee, Electron. Mater. Lett. 12, 127 (2016).

13. J. Schneider, A. Sarikov, J. Klein, M. Muske, I. Sieber, T. Quinn, et al., J Cryst. Growth 287, 423 (2006).

14. O, Nast, S. R. \& Wenham, J Appl. Phys. 88, 124 (2000).

15. C. Jaeger, M. Bator, S. Matich, and M. Stutzmann, J Appl. Phys. 108, 113513 (2010).

16. D. V. Gestel, I. Gordon, and J. Poortmans, Sol. Energ. Mat. Sol. C 119, 261 (2013). 